
VOLUME 10 NOMOR 6 DESEMBER 2021

ISSN : 2303-1514 | E-ISSN : 2598-5949

\title{
PENGARUH CERITA WAYANG SUKURAGA TERHADAP PENDIDIKAN KARAKTER SISWA DI KELAS TINGGI SEKOLAH DASAR
}

\author{
Nurul Amalia ${ }^{1}$, Iis Nurasiah ${ }^{2}$, Dyah Lyesmaya ${ }^{3}$, Yoesrina Novia Vini Syafitri ${ }^{4}$ \\ 1,2,3 Pendidikan Guru Sekolah Dasar Universitas Muhammadiyah Sukabumi, Indonesia \\ ${ }^{4}$ Pendidikan Dasar Sekolah Pascasarjana Universitas Pendidikan Indonesia, Indonesia \\ Iamalia.nurul797@gmail.com, ${ }^{2}$ iisnurasiah@ummi.ac.id, ${ }^{3}$ lyesmaya_dyah@ummi.ac.id, \\ 4yoesrinanovia06@upi.edu
}

\section{THE EFFECT OF THE SUKURAGA PUPPET STORY ON STUDENTS' CHARACTER EDUCATION IN UPPER CLASSES OF ELEMENTARY SCHOOL}

\begin{tabular}{|c|c|}
\hline ARTICLE HISTORY & ABSTRACT \\
\hline $\begin{array}{l}\text { Submitted: } \\
20 \text { September } 2021 \\
20^{\text {th }} \text { September } 2021\end{array}$ & $\begin{array}{l}\text { Abstract: This study aimed to determine the effect of the Sukuraga puppet story on the student's } \\
\text { character education in elementary schools. This study utilized a quasi-experimental type of } \\
\text { quantitative approach. The design used in this research is the Nonequivalent Control Group } \\
\text { Design. The subjects used in the study were } 4^{\text {th }} \text {-grade students of SDN Suryakencana CBM. The } \\
\text { data collection tool in this study used a questionnaire using a Likert scale measurement } \\
\text { consisting of } 20 \text { statements with the answers to statements including Always }(S L) \text {, Often }(S R) \text {, } \\
\text { Sometimes }(K K) \text {, Rarely (J), Never (TP). ) based on a checklist }(\sqrt{ }) \text { on the attitude scale } \\
\text { instrument grid. Based on the results of data processing pretest and posttest, with the } \\
\text { calculation of the t-test carried out with the help of the IBM SPSS version software } 26 \text { with the } \\
\text { results of planting character education using the Sukuraga puppet story, it obtained sig (2- } \\
\text { tailed) } 0.000 \text { which is less than }=0.05 \text {. Based on the results from this calculation, it can be } \\
\text { concluded that the story of the wayang Sukuraga affected the character education of students. }\end{array}$ \\
\hline
\end{tabular}

Keywords: Influence, Sukuraga Puppet Story, Character Education

Accepted:

12 Oktober 2021

$12^{\text {th }}$ October 2021

Abstrak: Penelitian ini memiliki tujuan guna mengetahui pengaruh cerita wayang sukuraga terhadap pendidikan karakter siswa di sekolah dasar. Penelitian ini menggunakan pendekatan kuantitatif jenis quasi eksperimental. Desain yang digunakan dalam penelitian adalah Nonequivalent Control Group Design. Subjek yang digunakan dalam penelitian adalah siswa kelas 4 SDN Suryakencana CBM. Alat pengumpulan data dalam penelitian ini menggunakan angket dengan memakai pengukuran skala likert yang terdiri dari 20 pernyataan dengan jawaban pernyataan antara lain: Selalu (SL), Sering (SR), Kadang-kadang (KK), Jarang (J), Tidak pernah (TP) dengan dilandaskan dalam bentuk checklist ( $($ ) pada kisi-kisi instrumen skala sikap. Berdasarkan hasil pengolahan data pretest dan posttest maka dengan perhitungan uji $t$ yang dilakukan dengan bantuan softwer IBM SPSS versi 26 dengan hasil penanaman pendidikan karakter menggunakan cerita wayang sukuraga mendapatkan sig (2-tailed) 0.000 yaitu kurang dari $\boldsymbol{\sigma}=0.05$. Berdasarkan hasil hitung tersebut dapat disimpulkan bahwa cerita

Published:

25 Desember 2021

25 December 2021

Kata Kunci: Pengaruh, Cerita Wayang Sukuraga, Pendidikan Karakter

\section{CITATION}

Amalia, N., Nurasiah, I., Lyesmaya, D., \& Syafitri, Y, N, V. (2021). Pengaruh Cerita Wayang Sukuraga Terhadap Pendidikan Karakter Siswa di Kelas Tinggi Sekolah Dasar. Primary: Jurnal Pendidikan Guru Sekolah Dasar, 10 (6), 1463-1470. DOI: http://dx.doi.org/10.33578/jpfkip.v10i6.8424. 


\section{PENDAHULUAN}

Pendidikan karakter berupaya agar seseorang memiliki rasa peduli, memahami, dan melakukan tindakan dengan dasar inti yang memiliki nilai yang sepadan dengan perilaku yang telah mendapatkan persetujuan. Pendidikan karakter memiliki nilai-nilai tersebut pada perkembangan pendidikan karakter yang berbudaya dan karakter yang berkebangsaan yaitu seperti disiplin, jujur, bertanggung jawab, mandiri, religius, kreatif, toleransi, bersahabat, rasa ingin tahu, peduli sosial, cinta damai, cinta tanah air, kerja keras, demokratis, peduli lingkungan, semangat bernegara, menghargai prestasi dan gemar membaca (Ma`arif, 2018: 32). Maka dari itu pendidikan karakter ini sangatlah diperlukan di mana-mana baik itu di rumah ataupun di lingkungan sosial bukan cuman di sekolah saja. Bahkan saat ini dari mulai remaja hingga usia dewasa mereka perlu pendidikan karakter bukan untuk anak usia dini saja, namun untuk kelangsungan hidup bangsa ini.

Pendidikan karakter adalah suatu sistem yang mencakup unsur tindakan, pemahaman, kehendak dan pengetahuan yang ditanam kepada masyarakat sekolah untuk melakukan nilai-nilai tersebut. Dan pendidikan moral atau budi pekerti yang mengandung arti dan hakikat yang serupa yaitu dengan pendidikan karakter, dengan tujuan agar terbentuknya personalitas lebih baik dari sebelumnya (Abdurrahman dan Ed, 2018: 5-6). Para peserta didik menjadi kelompok yang diterima dimasyarakat sekitar dan menjadi orang yang baik di dalam kehidupan bernegaraan dan pendidikan yang mengenai akhlak di sekolah. Pendidikan karakter merupakan keadaan dengan berusaha mengahadapi keadaan saat ini dalam pergeseran karakter. Tujuan dari pendidikan karakter ini agar berkembangnya kemampuan seseorang untuk menyampaikan hal yang baik atau buruk dalam keputusannya, apa yang baiknya dijaga, serta melaksanakan kesehariannya dengan kebaikan yang bersungguhh-sungguh (Komara, 2018: 18).

Keadaan warga Indonesia saat ini merasa tidak tenang dengan adanya berbagai kejadian yang memperlihatkan bahwa generasi muda Indonesia memiliki karakter dan moral yang rendah. Pertelevisian Indonesia dan media masa kerap kali memberitakan berbagai macam kejadian yang kurang terpuji sebagai berita utama. Seperti kekerasan, perusakan, korupsi, dan kehidupan politik yang tidak produktif (Rosita, 2016: 54). Kejadian tersebut mengisyaratkan bahwa lemahnya karakter bangsa dan rapuhnya karakter sangat mengkhawatirkan, terlebih dengan perkembangan teknologi komunikasi dan informasi yang memberikan kemudahan dengan datangnya informasi dari luar. Hanya bangsa yang berkarakter kuat lah yang mampu memilah informasi dan menggunakan teknologi dengan cermat.

Adapun penelitian terdahulu berkaitan dengan pembelajaran pendidikan karakter dengan menggunakan media komik Wayang Anak Pandawa oleh Pandawangi dan Nuryantiningsih (2018). Penelitian ini menghasilkan peningkatan pada pendidikan karakter hingga membentuk karakter peserta didik menjadi insan yang bermoral. Wayang adalah sebuah cerita kepahlawanan yang menceritakan para tokoh yang memiliki kepribadian baik dan kemunculan tokoh jahat ia musnahkan. Terbukti bahwa wayang telah melalui generasi ke generasi dan berbagai peristiwa sejarah, dan menunjukan bahwa telah melekat budaya perwayangan yang menjadi bagian hidup khususnya Jawa dan bangsa Indonesia sekitarnya. Perubahan segala aspek budaya dalam perwayangan ini mampu mempertahankan dan menyesuaikan perkembangan zaman. Wayang adalah kehidupan yang berisikan sanepa, piwulang, dan pituduh. Wayang mengandung arti kebiasan hidup, tingkah laku manusia sejak lahir, hidup, dan kemudian meninggal itu semua merupakan proses alamiah.

Di Jawa Barat khususnya di daerah 
Sukabumi terdapat wayang, yang bernama Wayang Sukuraga. Akan tetapi wayang sukuraga ini lebih dikenal di negara lain dibandingkan dengan rumah sendiri (Sukabumiupdate, 2018). Berdasarkan hasil observasi awal dengan pencipta wayang sukuraga pada tanggal 24 Desember 2020 menyatakan bahwa wayang sukuraga bisa digunakan sebagai media pendukung pendidikan karakter. Sukuraga merupakan gabungan dari dua suku kata, ialah "suku" yang bermakna kelompok atau anggota dan "raga" yang memiliki makna badan manusia, saat kata sukuraga digabungkan yang berarti anggota badan. Dalam artian wayang sukuraga adalah wayang atau boneka anggota badan. Wayang sukuraga memiliki konsepsi membangun citra visual perwujudan dari anggota badan manusia (Suardi et al, 2016: 3). Peran dan karakter dalam Sukuraga ini menceritakan tantang kehidupan dan kebiasaan yang dilakukan oleh bagian dari tubuh manusia itu sendiri. Dengan menggunakan wayang sukuraga ini agar manusia mengingat bahwa setiap perbuatan akan diminta pertanggung jawabannya sesuai dengan apa yang mereka kerjakan.

Berdasarkan pemaparan latar belakang yang telah disampaikan, maka peneliti bermaksud menerapkan cerita wayang sukuraga dalam pendidikan karakter siswa. Dengan penelitian yang berjudul "Pengaruh Cerita Wayang Sukuraga terhadap Pendidikan Karakter Siswa di Kelas Tinggi Sekolah Dasar" guna mengetahui pengaruh dari cerita wayang sukuraga terhadap pendidikan karakter siswa di kelas tinggi sekolah dasar.

\section{KAJIAN TEORI}

Pendidikan karakter adalah usaha membiasakan prihal yang baik agar peserta didik bisa mengerjakan sesuatu dengan bersikap dan mengambil tindakan sesuai dengan nilai-nilai kepribadian. Kemudian proses membangunnya karakter dilakukan dengan cara pendekatan integrative dan sistematik yang bersangkutan dengan pemerintah, satuan pendidikan, masyarakat sipil, media massa, anggota legislatif, dunia industry, dunia usaha, dan yang terpenting adalah keluarga (Susanti, 2013: 481). Menurut Sudrajat (2011: 48) bahwa karakter bersumber dari bahasa yunani yakni Charassein yang artinya character, yaitu to engrave (menggambar, melukis), sama halnya dengan manusia yang sedang memahat batu atau metal, dan kertas yang dilukis. Melihat dari pengertian yang sudah dari terdahulu bahwa character diartikan menjadi suatu ciri atau tanda yang khusus, oleh karenanya lahirlah satu pendapat bahwasanya karakter ialah bentuk tingkah laku yang mempunyai sifat perseorangan atau individual dan keadaan moral atau perbuatan seseorang. moral atau perbuatan seseorang.

Pendidikan karakter ini bukan hanya membiasakan anak menjadi berprilaku yang baik, akan tetapi lebih dari itu. Yaitu agar menjadikan anak berhasil dengan terbentuknya watak, pikiran, dan berperilaku yang baik. Pentingnya pendidikan karakter terdapat pada Quran surat Luqman ayat 17 (Agama, Negeri, dan Curup, 2018: 38).

Allah Subhanahu Wa Ta'ala berfirman:

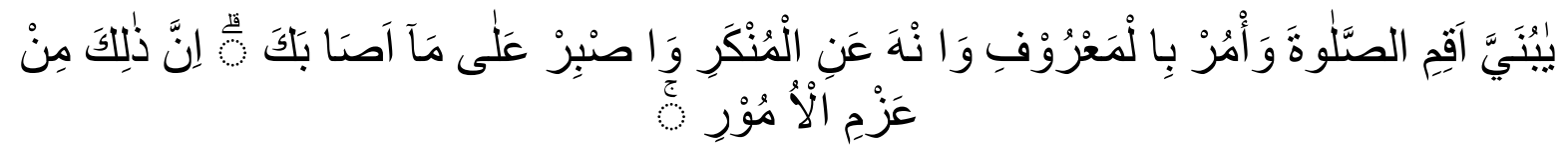


"Wahai anakku! Laksanakanlah sholat dan suruhlah (manusia) berbuat yang makruf dan cegahlah (mereka) dari yang mungkar dan bersabarlah terhadap apa yang menimpamu, sesungguhnya yang demikian itu termasuk perkara yang penting". (QS. Luqman 31: Ayat 17) Dalam ayat AlQuran tersebut menguraikan tentang dianjurkannya manusia untuk mendirikan kebenaran yaitu dapat membedakan dan memahami antara yang baik dan yang buruk dan menjauhkan dari perbuatan yang mungkar atau perbuatan yang durhaka.

Susanti (2013: 481) menambahkan bahwa pendidikan karakter ini adalah untuk mempengaruhi karakter siswa yang diterapkan dari usaha yang telah dilakukan oleh pendidikan karakter. Sehingga karakter ini menjadi identitas khusus yang dapat membandingkan satu orang dengan orang yang lainnya. Dan karakter ini membentuk siapa dan bagaimana pribadi orang sesungguhnya (Abdurrahman dan Ed, 2018: 3). Adapun tujuan dari pendidikan karakter itu sendiri adalah agar siswa memiliki dasar pengetahuan, kepribadian, kecerdasan, berakhlak mulia, dan kecakapan agar mampu hidup secara mandiri serta mampu mengikuti pendidikan lebih lanjut (Kemendiknas, 2018: 232).

Putry (2018: 45-46) menjelaskan bahwa terdapat 18 nilai agar terbentuknya karakter, ini merupakan sumber dari pancasila, budaya, agama dan tujuan dari pendidikan nasional yang meliputi religius, jujur, toleransi, disiplin, kerja keras, kreatif, mandiri, demokratis, rasa ingin tahu, semangat kebangsaan, cinta tanah air, menghargai prestasi, komunikatif/ bersahabat, cinta damai, gemar membaca, peduli lingkungan, peduli sosial, tanggung jawab.

Wayang sukuraga ini merupakan khas seni tersendiri dari Kota Sukabumi yaitu kota kelahirannya, yang kemudian berpadu dengan sastra, musik, seni rupa, dan teater wayang. Wayang sukuraga ini bebeda dengan wayang lainnya karena tidak mengangkat dari keterampilan wayang budaya Mahabarata dan Ramayana melainkan dari kehidupan sehari-hari apa yang dilakukan oleh manusia (Wikipedia, 2016). Dalam cerita wayang ini menceritakan tentang kebaikan, keburukan, dan sebagai petunjuk bahwa ada keadaan yang mesti dikerjakan dan yang tidak boleh dilkerjakan bagi semua anggota tubuh. Cerita wayang ini berbeda dengan cerita Wayang lainnya yang tidak merujuk pada cerita Mahabharata dan Ramayana, melainkan cerita wayang sukuraga yang diambil dari kegiatan masyarakat yang dilakukannya sehari-hari. Dalam cerita wayang ini menceritakan tentang kebersamaan, konflik, bergotong royong, berbeda namun satu tujuan semua ini yang merupakan simbol dari Bineka Tunggal Ika.

\section{METODE PENELITIAN}

Pendekatan penelitian yang digunakan dalam penelitian ini adalah pendekatan kuantitatif dengan jenis Quasi Eksperimental. Desain penelitian yang digunakan pada penelitian ini yaitu Nonequivalent Control Group Design. Menurut (Sugiyono, 2018: 116) pada desain nonequivalent control group design, untuk kelas kontrol dan kelas eksperimen pada penentuan kelas tersebut tidak ditentukan secara acak. Adapun populasi dalam penelitian ini adalah siswa kelas IV 
SDN Suryakencana CBM. Teknik pengambilan sampel pada penelitian ini adalah sampling jenuh. Sugiyono (2018: 124) berpendapat bahwa sampling jenuh merupakan teknik penentuan sampel penelitian yang diambil dari seluruh populasi untuk dijadikan sampel. Sampel penelitian ini yaitu terdiri kelas 4.2 dan kelas 4.4 yang dipilih untuk kelas eksperimen dan kelas kontrol.

Pada penelitian ini menggunakan angket dengan memakai pengukuran skala likert yang terdiri dari 20 pernyataan dengan jawaban pernyataan antara lain: Selalu (SL), Sering (SR), Kadang-kadang (KK), Jarang (J), Tidak pernah (TP) dengan dilandaskan dalam bentuk checklist $(\sqrt{ })$ pada kisi-kisi instrumen skala sikap. Pengumpulan data dilakukan pada saat pelaksanaan pretest dan post-test. Pretest ini bertujuan guna mengetahui pendidikan karakter siswa saat pembelajaran tematik berlangsung, apakah siswa sudah menguasai pendidikan karakter yang terdapat pada buku guru sebelum diberi tindakan sekaligus untuk memilih kelas eksperimen dan kelas kontrol berdasarkan hasil pretest. Kemudian tujuan dari posttest yaitu untuk mengetahui adanya pengaruh dari cerita wayang sukuraga terhadap pendidikan karakter siswa setelah diberikan tindakan, juga menganalisis keadaan perbedaan dari kelas kontrol dan kelas eksperimen.

\section{HASIL DAN PEMBAHASAN}

Berdasarkan hasil analisis dari hasil pretest menyatak bahwa nilai rata-rata kemampuan awal yaitu 73,40 , sedangkan 78,36 adalah nilai rata-rata kemampuan awal siswa dari kelas kontrol. Perolehan nilai skor maksimalnya yaitu 90 dan skor
55 adalah skor minimal yang diperoleh dari kelas eksperimen, sedangkan kelas kontrol memperoleh skor maksimal 91 dan skor minimal 65 . Untuk simpangan baku pada kelas eksperiman yaitu 8.226 dan 7.187 adalah simpangan baku dari kelas kontrol. Varians dari kelas eksperimen yaitu 67.667 dan dari kelas kontrol adalah 51.657.

Rata-rata nilai yang didapatkan pada hasil posttest siswa dengan jumlah siswa 25 orang dengan menggunakan cerita wayang sukuraga pada kelas eksperimen yaitu sebesar 85.16. Untuk skor maksimalnya adalah 94 dan skor minimalnya 78 . Dengan simpangan baku 5.006 dan 25.057 pada variansnya. Sedangkan untuk kelas kontrol dengan menggunakan pembelajaran langsung atau metode ceramah mendapatkan nilai ratarata posttestnya sebesar 81.64. Untuk skor maksimalnya adalah 90 dan 70 untuk skor minimalnya. Pada simpangan baku kelas kontrol yaitu sebesar 5.880 dan variansnya 34.573.

Pada analisis data ini menghasilkan data bahwa dari nilai pretest dan nilai posttest mendapatkan sig (2-tailed) 0.000 yaitu kurang dari $a=0.05$ sehingga $\mathrm{H}_{0}$ ditolak karena dari hasil pretest ke hasil posttest terdapat perbedaan. Artinya, kemampuan akhir siswa (posttest) dengan menggunakan cerita wayang sukuraga terhadap pendidikan karakter siswa di kelas eksperimen memiliki perbedaan.

Sementara pada kelas kontrol mendapatkan rata-rata pretest sebesar 78.36 dan untuk rata-rata posttest mendapatkan nilai sebesar 81.64. Dengan menggunakan uji $\mathrm{t}$ berpasangan ini pada analisis data dari hasil data pretest dan posttest memperoleh nilai signifikansi (2- 
tailed) > dari 0.05 yaitu 0.100 sehingga $\mathrm{H}_{0}$ diterima. Karena pada hasil tersebut tidak terdapat perbedaan yang signifikan dari hasil posttest dan pretest. Maka, tidak dapat perbedaan kemampuan akhir siswa (posttest) dengan menggunakan pembelajaran langsung terhadap pendidikan karakter siswa di kelas kontrol.

Hasil pengujian dari uji PairedSamples $T$ Test dari kelas eksperiman mendapatkan nilai sig 0.000. Sedangkan nilai dari kelas kontrol mendapatkan nilai sig 0.100. Pada kelas eksperimen karena mendapatkan sig > 0.05 maka $\mathrm{H}_{0}$ ditolak dan $\mathrm{H}_{1}$ diterima dan pada kelas kontrol

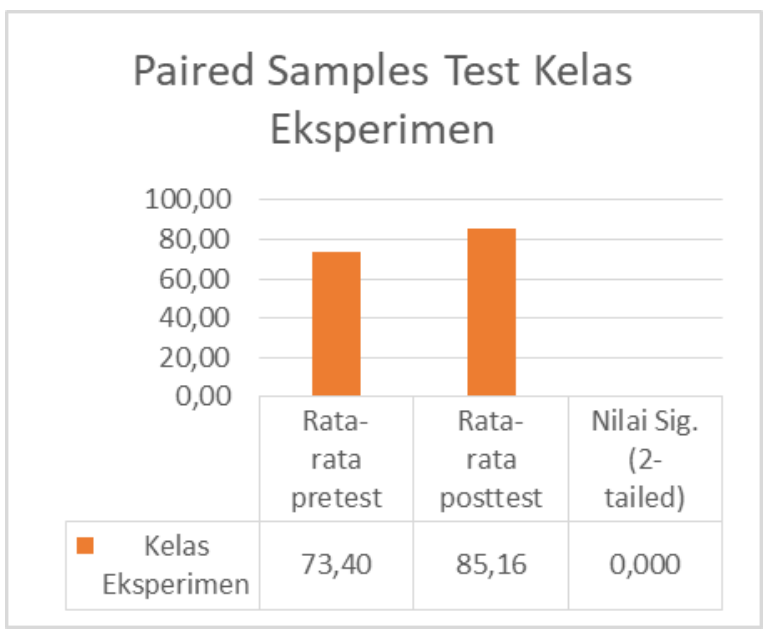

mendapatkan sig $>0.05$ dengan begitu $\mathrm{H}_{0}$ diterima dan $\mathrm{H}_{1}$ ditolak. Selesai dilakukannya pengujian menggunakan uji Paired-Samples T Test maka bisa kita lihat terdapat perbedaan dari hasil pretest dan hasil posttest pada kelas eksperimen. Namun, dari hasil pretest dan hasil posttest pada kelas kontrol tidak terdapat perbedaan. Peningkatan pendidikan karakter siswa dengan menggunakan cerita wayang sukuraga di kelas eksperimen dan di kelas kontrol dengan pembelajaran langsung dapat dilihat pada diagram berikut ini:

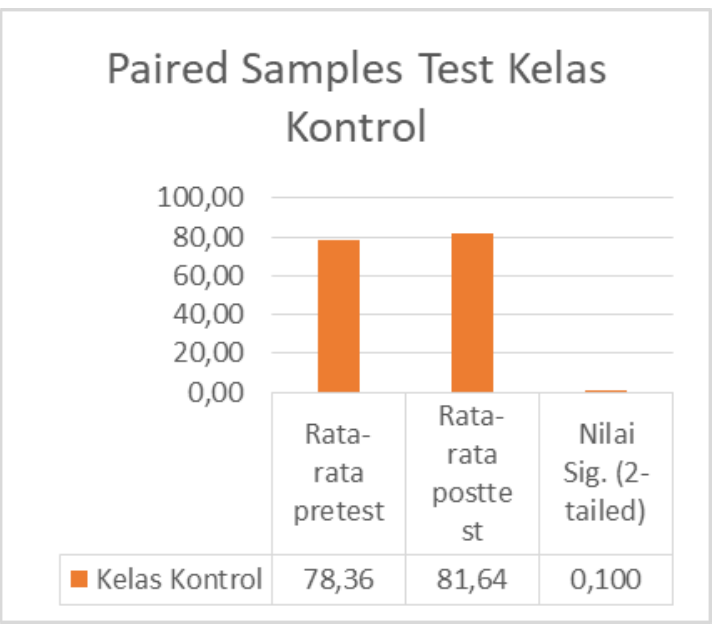

Gambar 1. Sample Tes Kelas Eksperimen dan Kontrol

Secara umum, hasil penelitian ini telah memberikan informasi bahwa dengan menggunakan cerita wayang sukuraga pada pembelajaran tematik tema 9 dapat meningkatkan pendidikan karkter siswa. Perihal tersebut terdapat pada hasil peningkatan kelas eksperimen yang diberikan perlakuan sedangkan kelas kontrol tidak diberikan perlakuan.

Hal ini sesuai dengan hipotesis penelitian yang diduga kemudian terdapat perbedaan peningkatan antara kedua kelas tersebut secara signifikan, hal tersebut merupakan hasil dari uji prasyarat analisis dan dilanjutkan dengan uji $t$ yang menghasilkan sig 0.000 yang artinya kurang dari $a=0.05$. Maka sehingga $\mathrm{H}_{1}$ diterima dan $\mathrm{H}_{0}$ ditolak. Dengan begitu hipotesis ini menyatakan bahwa adanya perbedaan yang signifikan pada pendidikan karakter siswa kelas IV SDN 
Suryakencana CBM sebelum dan sesudah menggunakan cerita wayang sukuraga.

\section{SIMPULAN DAN REKOMENDASI}

Berdasarkan hasil dan pembahasan yang telah dipaparkan di atas, maka dapat disimpulkan bahwa penggunaan cerita wayang sukuraga dapat meningkatkan pendidikan karakter siswa di kelas IV sekolah dasar. Hal ini terlihat dari nilai rata-rata pada pretest sebesar 73.40 dan pada hasil posttest mendapatkan hasil nilai rata-rata senbesar 85.16. Pada analisis data ini menghasilkan data bahwa dari nilai pretest dan nilai posttest mendapatkan sig (2-tailed) 0, 000 yaitu kurang dari $a=0.05$ sehingga $\mathrm{H}_{0}$ ditolak karena dari hasil pretest ke hasil posttest terdapat perbedaan. Artinya, kemampuan akhir siswa (posttest) dengan menggunakan cerita wayang sukuraga terhadap pendidikan karakter siswa di kelas eksperimen memiliki perbedaan. Sementara pada kelas kontrol mendapatkan rata-rata pretest sebesar 78.36 dan untuk rata-rata posttest mendapatkan nilai sebesar 81.64. Dengan menggunakan uji t berpasangan ini pada analisis data dari hasil data pretest dan posttest memperoleh nilai signifikansi (2-tailed) > dari 0.05 yaitu 0.100 sehingga $\mathrm{H}_{0}$ diterima. Karena pada hasil tersebut tidak terdapat perbedaan yang signifikan dari hasil posttest dan pretest. Maka, tidak dapat perbedaan kemampuan akhir siswa (posttest) dengan menggunakan pembelajaran langsung terhadap pendidikan karakter siswa di kelas kontrol. Menurut simpulan yang telah dipaparkan peneliti memiliki beberapa saran yang hendak disampaikan sebagai upaya peningkatan kualitas pendidikan khususnya pada pendidikan karakter siswa.
Rekomendasi dari hasil penelitian ini adalah sebagai masukan dan sebagai penerapan terhadap pendidikan karakter dengan menggunakan cerita wayang sukuraga dan dapat menerapkan penggunaan cerita wayang sukuraga dalam proses belajar mengajar dalam pendidikan karakter di sekolah.

\section{UCAPAN TERIMA KASIH}

Alhamdulillahirabbil'alamin, ucapan terimakasih ini ditunjukan kepada semua pihak yang telah membeikan bantuan, dorongan, semangat serta bimbingan selama pelaksaan dan penulisan penlitian hingga dapat menyelesaikan peneletian ini. Dengan segala kerendahan hati, penulis menyampaikan terimakasih kepada SDN Suryakencana CBM yang sudah memberikan perizinan untuk melaksakan penelitian ini.

\section{DAFTAR PUSTAKA}

Abdurrahman, M. (2018). Pendidikan Karakter Bangsa. Jurnal Pendidikan, 2(1), 20-25.

Komara, E. (2018). Penguatan Pendidikan Karakter Dan Pembelajaran Abad 21. SIPATAHOENAN: South-East Asian Journal for Youth, Sports \& Health Education 4(1): 17-26. www.journals.mindamas.com/index.ph p/sipatahoenan.

Ma`arif, M. A. (2018). Analisis Strategi Pendidikan Karakter Melalui Hukuman Preventif. Ta'allum: Jurnal Pendidikan Islam, 6(1), 31-56.

Putry, R. (2018). Nilai Pendidikan Karakter Anak Di Sekolah Perspektif Kemendiknas. Jurnal Cakrawala, 4(1), $39-54$

Rosita, M. (2016). Membentuk Karakter Siswa Melalui Metode Kisah Qurani. FITRAH: Jurnal Kajian Ilmu-ilmu Keislaman, 2(1), 53.

Suardi, A., et al. (2016). Wayang Sukuraga 
ISSN : 2303-1514 | E-ISSN : 2598-5949

Dari Bahasa Rupa Ke Bahasa Pertunjukan. Pantun Jurnal Ilmiah Seni Budya (62).

Sudrajat, A. (2011). Mengapa Pendidikan Karakter?. Jurnal Ilmiah, 5(5), 47-58.

Sugiyono. (2018). Metode Penelitian

Pendidikan Pendekatan Kuantitatif, Kualitatif, Dan R\&D. 27th ed. Bandung: ALFABETA.
Susanti, R. (2013). Penerapan Pendidikan Karakter Di Kalangan Mahasiswa. AlTa'lim, 9(2), 480-87.

Pandawangi, N. (2018). Komik Wayang Anak Pandawa Sebagai Media Pendidikan Karakter Di Jaman Kekinian. JOM 8(3), 1-10.

Wikipedia. (2016). "Wayang Sukuraga." https://id.wikipedia.org/wiki/Wayang_ Sukuraga. 